\title{
Casa das Rosas: resistência poética no caos paulistano
}

Frederico Barbosa

Poeta, autor de, entre outros, Nada feito nada e Brasibraseiro. Diretor do Espaço Haroldo de Campos de Poesia e Literatura (Casa das Rosas).

E-mail: fredericobarbosa@casadasrosas.sp.gov.br

Donny Correia, colaborador

Poeta e autor de O eco do espelho. Coordenador cultural do Espaço Haroldo de Campos de Poesia e Literatura (Casa das Rosas).

E-mail: donnycorreia@casadasrosas.sp.gov.br

Depois de cerca de dois anos fechada, a Casa das Rosas foi reaberta ao público em 9 de dezembro de 2004 pelo governador de São Paulo, Geraldo Alckmin, com o intuito ímpar de se transformar em pólo irradiador de poesia e literatura. Às novas funções, acrescentou-se também uma nova designação: Espaço Haroldo de Campos de Poesia e Literatura, em homenagem ao grande poeta falecido em 2003, cuja biblioteca, com cerca de 35.000 volumes, a Casa passou a abrigar.

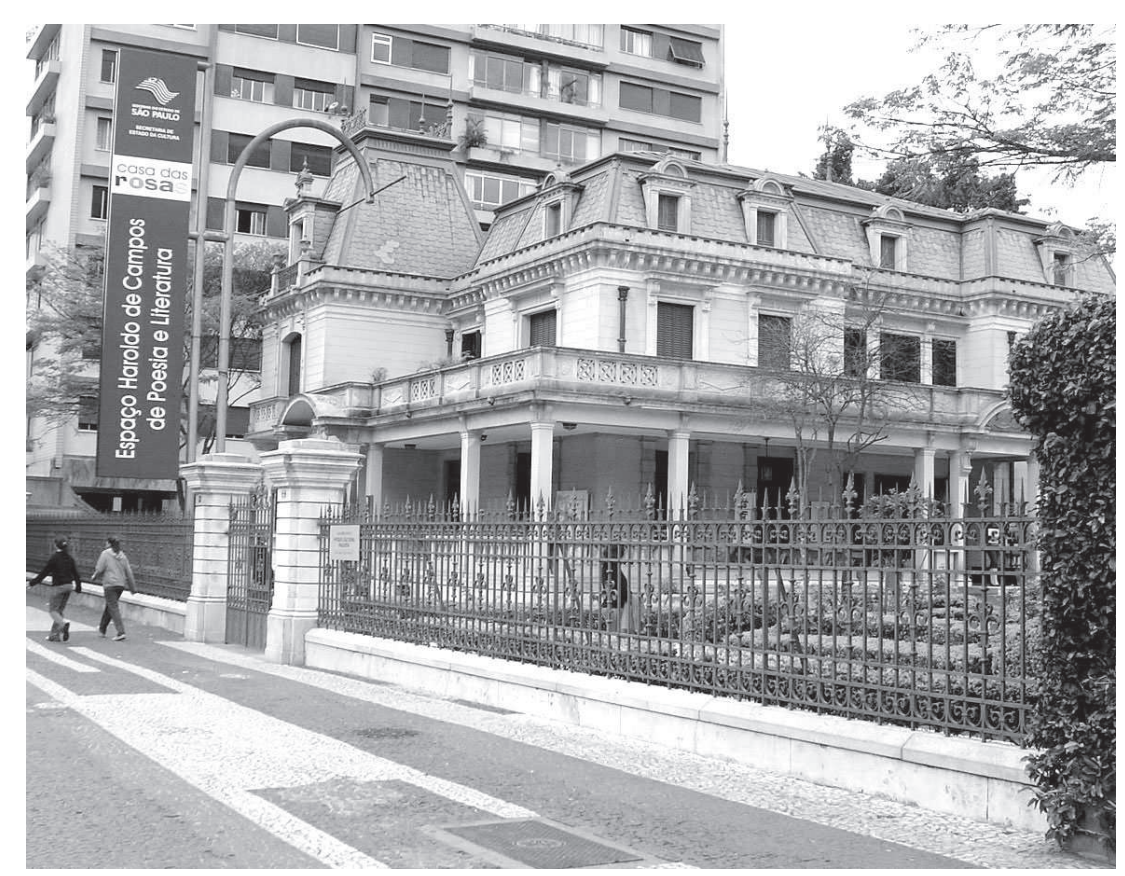

Casa das Rosas: um marco na avenida Paulista. 
O poeta de campos e espaços notabilizou-se pelo esforço de manter viva a poesia, defendendo o prazer sem limite de jogar com as palavras. É essa a missão do seu Espaço. Poesia é resistência. Resistência ao caos, resistência à rapidez indiferente da contemporaneidade, resistência ao vácuo mental do presente. Uma luta sem garantias e sem um ideal muito definido além da criação contra as agruras do cotidiano. Nesse sentido de luta e resistência, o Estado de São Paulo deu uma contribuição essencial quando reabriu as portas da Casa das Rosas para o público. Uma mansão da década de 1930 que, por mais de dez anos, foi uma galeria de artes e exposições, agora se tornou o primeiro centro cultural público dedicado prioritariamente à poesia e à literatura do Brasil.

Além da Biblioteca Haroldo de Campos, em fase de catalogação, há, na mansão localizada à avenida Paulista, 37, uma biblioteca circulante, especializada em poesia, uma livraria da Imprensa Oficial, salas de leitura, sala de exposições e diversos cursos gratuitos para os interessados.

\section{A CASA DOS RAMOS DE AZEVEDO}

Em 1928, o escritório do arquiteto Francisco de Paula Ramos de Azevedo já era tido como o mais famoso e reputado da área na América Latina. Ramos de Azevedo era paulista e havia estudado arquitetura na Bélgica; formou-se com louvor e consagrou-se igualmente em Paris. De volta ao Brasil, projetou e executou diversos prédios de importância histórica hoje, tais como: Pinacoteca do Estado, Theatro Municipal, Prédio da Light, Mercado Público de São Paulo, entre outros.

No fim de sua vida, projetou a Casa das Rosas, uma mansão em estilo clássico francês que seria dada de presente à sua filha que estava para se casar. Com seus trinta cômodos, edícula, jardins, quadras e pomar, a Casa das Rosas estava situada na avenida Paulista, local que reunia a maioria dos milionários barões do café.

Ramos não viveu para ver a obra concluída, pois morreu em 12 de junho de 1928. A construção prosseguiu e a Casa das Rosas foi concluída em 1935. Lá, os

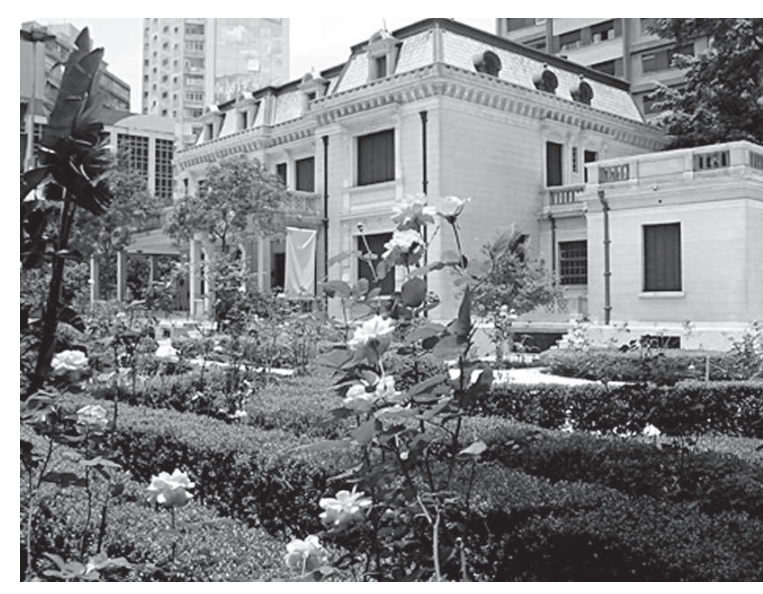

A mansão Casa das Rosas, construída em estilo clássico francês. herdeiros de Ramos de Azevedo viveram até meados dos anos 1980, quando o neto do arquiteto faleceu e sua esposa, Ana Rosa, mudou-se. Por essa época, a avenida Paulista já não era mais a mesma. A Casa das Rosas, outrora localizada no canto mais intimista daquela Paulista dos anos 1930 - vale lembrar que a família Ramos de Azevedo prezava pela privacidade, tendo nas dependências da casa inclusive uma barbearia particular para evitar as 
saídas -, já nos anos 1980 dividia espaço com prédios comerciais, bancos, edifícios modernos e o característico trânsito de pessoas e veículos.

Para atender ao progresso implacável, muitas mansões anteriores à Casa das Rosas foram derrubadas para dar espaço à modernização. O mesmo já se cogitava para a obra de Ramos de Azevedo, quando o Estado optou por transformar o local em patrimônio histórico. Isso feito, a casa passou por um processo de restauração a partir de 1986 e, em 1991, foi inaugurada como Galeria de Artes Casa das Rosas. Assim permaneceu até 2003, quando a então secretária de cultura, Claudia Costin, decidiu-se por dar novos rumos ao lugar.

\section{HAROLDO DE CAMPOS E A POESIA CONCRETA}

Enquanto São Paulo passava por um intenso processo de industrialização e progresso, que quase engoliu a Casa das Rosas, vários movimentos culturais tomavam corpo na cidade.

Um momento em que a literatura paulistana representou o que de mais fundamental e avançado se produzia na época não só em nosso país, mas em todo o mundo, foi no final da década de 1950, quando surgiu a poesia concreta.

Tirando o nome de uma palavra misteriosa, utilizada pelo trovador provençal Arnault Daniel e comentada por Ezra Pound no Canto XX dos seus Cantares, que posteriormente descobriram significar "antídoto do tédio", três jovens paulistas, com pouco mais de 20 anos de idade, formaram, em 1952, o grupo Noigandres, que acabaria por revolucionar a poesia mundial. Reagindo contra o formalismo academicista da retrógrada geração de 1945 e procurando recuperar o espírito permanentemente revolucionário de 1922, Décio Pignatari e os irmãos Haroldo e Augusto de Campos investigavam, ao mesmo tempo que outros poucos jovens o faziam na Europa, como o suíço Eugen Gomringer, as possibilidades de uma poesia que fosse além do verso e

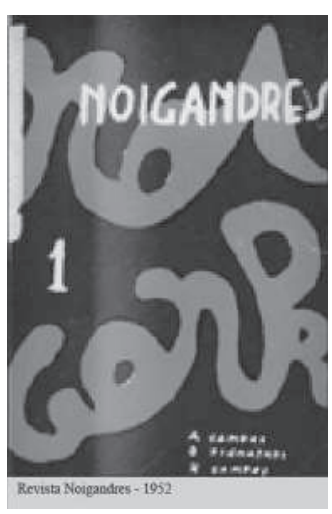
procurasse novas formas de expressão.

Demonstrando uma riqueza cultural descomunal, que nada ficava devendo aos seus contemporâneos europeus ou americanos, e, por isso mesmo, livres da xenofobia covarde ou do complexo de inferioridade subserviente - os dois opostos complementares que sempre marcaram (e marcam) a maioria dos intelectuais e escritores brasileiros -, eles se propõem, desde o início, a realizar a proeza sonhada pelo antropófago Oswald de Andrade de produzir, no Brasil, uma literatura de teor, qualidade e importância universais.

Assim, em 1953, Augusto de Campos, aos 22 anos, compõe uma série de poemas coloridos e dispostos de maneira original na página. Inspirados na música de vanguarda de Anton Webern, os textos de Poetamenos podem ser considerados os primeiros exemplos da poesia concreta. No final de 1956, o grupo Noigandres organizou, com artistas plásticos e outros poetas que aderiram ao movimento, uma exposição em São Paulo, transposta no início de 1957 para o Rio de Janeiro, em que a poesia concreta foi lançada para o Brasil e para o mundo. 
Começava então a polêmica recepção do movimento revolucionário, que já dura quase cinco décadas. A revista O Cruzeiro de março de 1957 trazia a seguinte manchete: "O rock'n'roll da poesia", sobre o surgimento da poesia concreta. A idéia é que fosse uma moda passageira e insignificante, maluca como a música que surgira poucos anos antes nos Estados Unidos. Duplo engano. Nem o rock nem a poesia concreta morreram. Nascendo na mesma época da bossa nova e do rock'n'roll, a poesia concreta é o primeiro estilo literário a surgir, se não antes, pelo menos ao mesmo tempo no Brasil e no resto do mundo. Numa literatura que sempre se viu atrelada às modas que vieram de fora, esse é um fenômeno único. Assim, a literatura paulistana confirmava sua tendência à ruptura conseqüente, sempre fundamentada na erudição de estudiosos como Décio Pignatari, Augusto e Haroldo de Campos. E, finalmente, conseguiu estabelecer a independência da nossa literatura em relação à européia, constituindo a vanguarda da literatura ocidental naquele momento.

Em agosto de 2003, Haroldo de Campos morreu aos 74 anos, em São Paulo. A sua família decidiu-se por doar ao Estado sua biblioteca particular, com obras fundamentais reunidas ao longo de anos de pesquisa em vários assuntos, como lingüística, semiótica, religião, filosofia, tradução etc.

De posse desse acervo, a Secretaria de Cultura anunciou que abrigaria todo o material a ser catalogado na Casa das Rosas, que seria, então, co-batizada Espaço Haroldo de Campos de Poesia e Literatura.

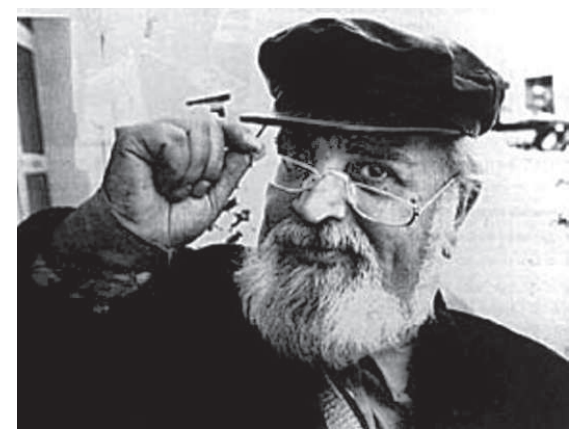

\section{UM OÁSIS POÉTICO NA PAULISTA}

Inaugurada oficialmente em 9 de dezembro de 2004, a Casa das Rosas - Espaço Haroldo de Campos de Poesia e Literatura veio para concretizar a luta em prol da poesia.

Rapidamente definidas as metas para a instituição, em janeiro de 2005 quatro cursos foram formulados: Estudo sobre a obra de Fernando Pessoa, Oficina de Criação Poética, Oficina de Haikai e Poesia Visual para Crianças. Além de uma espécie de pocket-curso intitulado Poesia Sobremesa, tratando-se de rápidos encontros (30 minutos) para o estudo de poetas diversos em ordem cronológica, sempre no horário de almoço. Esse curso ainda permanece na grade de programação e não tem uma seqüência obrigatória, o que possibilita ao público freqüentá-lo de acordo com a disponibilidade de cada um. Eventualmente, o Poesia Sobremesa foi renomeado para Poesia Aperitivo, mais adequado para o horário em que acontece (de $12 \mathrm{~h} 20$ até $12 \mathrm{~h} 50$ ), como se fosse um antepasto aos executivos, funcionários e visitantes que têm a via de acesso obrigatória no horário de almoço.

Quanto aos outros cursos, o que parecia utopia aconteceu: programados para ter somente uma turma cada, logo todos foram ampliados, com a criação de novas turmas para atender a procura acima de qualquer expectativa. Não 
demorou muito para que a poesia passasse a ter espaço na mídia e a Casa das Rosas deu continuidade a uma série de ações que vêm se prolongando por todo o ano.

\section{AÇÕES}

De uma grade composta por quatro cursos com duração de um mês, o Espaço Haroldo de Campos ampliou o número de assuntos a serem estudados e repetiu os cursos que foram sucesso, o que tem acontecido com freqüência. $\mathrm{O}$ curso que trata da vida e obra de Fernando Pessoa repetiu-se por três meses seguidos, sempre com aproveitamento total das vagas (em média 50 por turma). A prova de que existem muitas pessoas que desejam dominar o ato do fazer poético e mostrar sua produção foi o curso de criação poética, que também se repetiu até junho.

Paralelamente aos carros-chefes da programação, surgiram novos cursos. De março até agora já passaram pelo Espaço diversos especialistas em vários assuntos literários para o ensino de temas como: literatura de cordel, Guimarães Rosa, Augusto dos Anjos, poesia marginal dos anos 1970, poesia contemporânea, semiótica, história da arte, história da MPB, entre outros.

A popularidade advinda dos cursos trouxe a necessidade de abrir os ciclos: palestras e apresentações de assuntos diversos para expandir a discussão dos temas relacionados à poética. Assim, desde abril, a Casa das Rosas - Espaço Haroldo de Campos de Poesia e Literatura oferece mensalmente quatro ciclos:

\section{Como e por que sou leitor}

Visando a uma conversa informal com o público, a Casa das Rosas busca figuras importantes do meio literário para uma entrevista pública sobre o ato de ler, como deu-se a descoberta da leitura na vida dessas figuras, como isso influenciou no futuro trabalho com as letras e, finalmente, a importância real de ler no mundo e nos dias de hoje. Passaram pelo palco do Como e por que sou leitor nomes de respeito como José Mindlin, Boris Schnaiderman, João Alexandre Barbosa, Jacó Guinsburg, José de Paula Ramos Jr. e Manuel da Costa Pinto.

\section{Rompendo o silêncio}

A poesia contemporânea tem pouquíssimo espaço nas discussões acadêmicas. Dentro das universidades, o estudo da poesia brasileira costuma terminar no período que compreende a segunda geração modernista e os primeiros passos da geração de 1945. Isso, com certeza, tem influenciado para que o ato de ler e escrever poesia sofra um engessamento progressivo até o limite do ostracismo absoluto. Em parceria com orientadores da Universidade de 
São Paulo, a Casa das Rosas promove encontros mensais com poetas contemporâneos que são estudados em dossiês previamente preparados por alunos do curso de Letras. Os dossiês são lidos para a platéia na presença do poeta convidado e este é, a seguir, entrevistado pelo autor do estudo e pela platéia presente. $\mathrm{O}$ evento acontece com a mesma informalidade que permeia o ciclo anterior. Por esse ciclo já passaram Glauco Mattoso, Alice Ruiz, Ademir Assunção, Cláudio Daniel e outros.

\section{Desconcertos na Paulista}

Da mesma discriminação acadêmica sofre a prosa contemporânea. Assim, escritores contemporâneos são convidados a ler trechos de suas obras, textos inéditos e de outros prosadores não conhecidos, mas que os agrade. O público participa ativamente dando opiniões sobre a obra do entrevistado e questionando-o. Autores como Joca Reiners Terron, Marcelino Freire, Ivana Moura, Nelson de Oliveira, Xico Sá, Márcia Denser, Mário Bortolotto e Marcelo Mirisola já passaram pelo Desconcertos na Paulista.

\section{Sexta básica}

A música também tem seu espaço dentro desse fomento à poesia promovido pelo Espaço Haroldo de Campos. Assim, desde março de 2005, artistas vêm à Casa mostrar a junção da música e da poesia. Diversos estilos e técnicas desfilam pelo palco do Sexta Básica. Num dos eventos que mais traz público, muitos músicos já tiveram a oportunidade de decolar numa carreira por conta da publicidade feita em torno na Casa das Rosas. Atualmente a direção do evento encontra-se nas mãos hábeis do paraibano Pedro Osmar, músico que já trabalhou com Zé Ramalho, Zeca Baleiro, Lenine e outros, e hoje, morando em São Paulo, descobre talentos ocultos na periferia da capital.

\section{BIBLIOTECAS HAROLDO DE CAMPOS E CIRCULANTE}

Como mencionado anteriormente, o acervo pessoal do poeta Haroldo de Campos foi abrigado nas dependências da Casa das Rosas. Desde o final de 2004, uma equipe trabalha incessantemente para catalogar cada volume da coleção. Obras raras, esgotadas e edições limitadas de diversos autores, com anotações feitas por Haroldo, estarão em breve disponíveis para pesquisadores, professores e autores.

Aos que mal podem esperar para conhecer esse rico acervo poético, a Casa das Rosas oferece a primeira biblioteca circulante especializada em poesia no Brasil. O acervo, ainda em formação - por isso contando com doações particulares e de editoras -, oferece uma gama espantosa de trabalhos poéticos. Autores mais e menos conhecidos podem ser consultados. Não só obras, mas 
estudos sobre obras podem ser gratuitamente emprestados aos membros da biblioteca. Para ter uma idéia, está lá, completa, a Coleção Signos, editada pela Perspectiva, sob direção de Haroldo de Campos. Uma coleção que, ainda hoje, visa a editar obras de valor inegável para a poesia, como, por exemplo, as de Julio Cortazar, Augusto de Campos, Cláudio Daniel, Carlos Ávila, entre outros.

\section{OUTRAS AÇÕES CULTURAIS E DE INCENTIVO}

A crescente procura pela Casa das Rosas - Espaço Haroldo de Campos de Poesia e Literatura levou o corpo administrativo a abrir novas frentes de incentivo a essa manifestação literária. Com isso, é cada vez maior o número de novos e jovens escritores que lançam seus livros em noites de autógrafos na Casa. Artistas expõem obras de poesia visual nas dependências do Espaço e companhias teatrais procuram o lugar para apresentar trabalhos que pedem um ambiente alternativo para valorizar a mensagem do espetáculo.

Por conta disso, durante o mês de julho, a Casa das Rosas cedeu espaço total a diversos grupos que apresentaram peças adaptadas de obras literárias de renome, como Molly, de Samuel Beckett, e Éden, de Haroldo de Campos. Por causa dessa aceitação tão surpreendente, a Casa das Rosas já está programando mais apresentações teatrais para o fim do ano.

Embora a prerrogativa do Espaço Haroldo de Campos seja difundir a poesia, o incentivo às outras vertentes culturais é garantido. Aos finais de semana, a Casa vira pólo de ensino e jogos de RPG para jovens e adultos, além de ser sempre um belo local de visitação histórica. Cerca de 5 mil pessoas por mês passam pela casa para conferir de perto a obra genial de Ramos de Azevedo, construída com material todo importado da Europa.

\section{VISÕES PARA O FUTURO}

A Casa das Rosas - Espaço Haroldo de Campos de Poesia e Literatura tem atuado firmemente não só no campo da poesia, mas da literatura em geral, teatro, música e artes. Para esse primeiro ano na atividade de um novo foco, o saldo é positivo, pois o espaço acolheu muitos interessados em conhecer, estudar e produzir. Para 2006, a grade de cursos, eventos, palestras etc. já está sendo definida. Com a certeza de ter adquirido uma experiência sólida durante 2005, a equipe do Espaço Haroldo de Campos arrisca até pensar na criação de uma escola livre de estudos e produção poética. Algo que seria inteiramente inédito no país e possibilitaria um aprofundamento ainda maior por parte daqueles que buscam a utilidade da poesia na vida e no mundo moderno, ou daqueles que sabem disso, mas não conseguem articular uma resposta.

Essa ação já teve início com a criação de grupos de estudo para diversas vertentes da poesia, como lírica moderna, poesia concreta e criação em grupo.

Vale dizer que por ser um órgão público, a Casa das Rosas - Espaço Harol- 
do de Campos de Poesia e Literatura oferece todas as atividades gratuitamente. Para os cursos, todos apostilados e ministrados por especialistas, há uma taxa de inscrição simbólica de R $\$ 10,00$.

Todas as ações expostas neste artigo têm, como pano de fundo, transformar a Casa das Rosas em um espaço dinâmico, "vivo", de leitura, produção e conhecimento de poesia e literatura, a fim de que se torne um centro de referência e estímulo para a poesia no Brasil. Eis o desafio e a luta.

\section{Casa das Rosas - Espaço Haroldo de Campos de Poesia}

Av. Paulista, 37.

Paraíso - São Paulo-SP - 012311-000 - Tel.: (11) 3285-6986

Aberto de terça a domingo, das 10 às $18 \mathrm{~h}$. Entrada franca

E-mail: contato@casadasrosas.sp.gov.br

Site: www.casadasrosas.sp.gov.br 